This item is the archived peer-reviewed author-version of:

Broadcasting the mind: extended cognition in Beckett's radio plays

\title{
Reference:
}

Beloborodova Olga, Verhulst Pim.- Broadcasting the mind: extended cognition in Beckett's radio plays

Beckett and modernism / Beloborodova, Olga [edit.]; et al. - ISBN 978-3-319-70373-2 - New York, N.Y., Palgrave Macmillan, 2018, p. $239-257$ Full text (Publisher's DOI): https://doi.org/doi:10.1007/978-3-319-70374-9_16 
This is the author's version of a chapter published by Palgrave Macmillan in Beckett and Modernism, ed. Olga Beloborodova, Dirk Van Hulle and Pim Verhulst (New York, 2018),

239-258. Please refer to the published version for correct citation and content. For more information, see https://www.palgrave.com/de/book/9783319703732.

\section{Broadcasting the Mind: Extended Cognition in Beckett's Radio Plays}

\section{Olga Beloborodova and Pim Verhulst}

(University of Antwerp)

In 2011, David Herman launched an appeal to 're-mind modernism' by reassessing the 'critical commonplace' of the so-called inward turn of narrative. Coined by Erich von Kahler in the $1950 \mathrm{~s},{ }^{1}$ the term has become known as a typically modernist phenomenon that shifts the focus of narrative enquiry 'from the detailed profiling and authentication of the fictional worlds in which characters' experiences unfold to capturing the mental or psychological texture of those lived experiences themselves' (Herman 2011: 243). Without disputing the increased attention the modernists paid to the workings of the (fictional) human mind, Herman attempts to nuance the way their interest in the cognitive has become 'tantamount to an "inward turn"" (248). In other words, he questions the presentation of the modernist fictional mind as an exclusively 'interior space', and disputes its exploration as 'a movement inwards' (248) in order 'to probe psychological depths' (249). Instead, Herman argues that 'modernist narratives can both be illuminated by and help illuminate postcognitivist accounts of the mind as inextricably embedded in contexts for action and interaction' (249), referring in particular to the non-representational theories of enactivism.

In this chapter, we use Herman's revision of modernism as a departure point on a journey into the realm of Beckett's fictional minds in his radio plays. In concrete terms, we will re-examine the plays from a postcognitivist angle, in order to highlight the mind/world nexus they are grounded in and the modifications it undergoes. As a result, a postcognitivist mind/world continuum will emerge - a continuum in which the Cartesian inside/outside boundary is increasingly called into question, as the mind and the storyworld tend to amalgamate in a barely distinguishable whole. ${ }^{2}$ This evolution is in line with Beckett's comment in his letter to Georges Duthuit of 9 March 1949 about the work of painter Bram van Velde:

We have waited a long time for an artist who is brave enough, is at ease enough with the great tornadoes of intuition, to grasp that the break with the outside world entails the break with the inside world, that there are no replacement relations for naive 
This is the author's version of a chapter published by Palgrave Macmillan in Beckett and Modernism, ed. Olga Beloborodova, Dirk Van Hulle and Pim Verhulst (New York, 2018),

239-258. Please refer to the published version for correct citation and content. For more information, see https://www.palgrave.com/de/book/9783319703732.

relations, that what are called outside and inside are one and the same. (LSB II 140; emphasis added)

The erosion of the inside/outside dichotomy gained prominence in L'Innommable, begun a mere three weeks later (Van Hulle and Weller 2014: 91), and it was still an issue in Beckett's radio plays, which he started writing in the mid-1950s, while translating the novel into English as The Unnamable. Moreover, the ephemeral nature of the radio medium may have deepened his understanding of this anti-Cartesian stance and was probably instrumental in shaping Beckett's own unique kind of modernism, one that eventually abandoned story in favour of discourse. He was more interested in showing how the mind works (or fails to work) rather than representing the characters' thoughts, albeit in original and innovative ways, as early and high modernists famously did. The following section will first outline how the more canonical modernists dealt with radio, before assessing Beckett's relationship to the medium by analysing his radio plays from a postcognitivist perspective.

\section{Modernism and radio}

Despite the fact that the British Broadcasting Company - later Corporation - was established in 1922, at the pinnacle of high modernism, modernist authors did not immediately find their way to radio. Elitist approaches to modernism, such as John Carey's controversial study The Intellectuals and the Masses (1992), have explained this as a disdain for, and even a distrust of radio as a mass medium, but more recent scholarship on the subject has largely debunked that myth and replaced it with a more nuanced and complex view. Todd Avery's 2006 book Radio Modernism: Literature, Ethics, and the BBC, 1922-1938 was a pioneering work in this respect, showing that key figures of the Bloomsbury Group, like Desmond MacCarthy and Virginia Woolf, but also T. S. Eliot and H. G. Wells, were attracted to the possibilities of broadcasting and participated in this form of cultural dissemination, the one more prolifically than the other. Since then, other names have been added to the list, including E. M. Forster, David Jones, George Orwell, Ezra Pound, J. B. Priestley, Gertrude Stein and W. B. Yeats (see Rae Cohen, Coyle and Lewty 2009; Feldman, Mead and Tonning 2014). However, the two main reasons why this 'heterogeneous group of writers took to the microphone', Avery concludes, were to 'read their own work' and 'to promote their cultural, political, social, and moral ideas' in what was commonly referred to as 'talks' (2006: 139). Apart from Ezra 
This is the author's version of a chapter published by Palgrave Macmillan in Beckett and Modernism, ed. Olga Beloborodova, Dirk Van Hulle and Pim Verhulst (New York, 2018),

239-258. Please refer to the published version for correct citation and content. For more information, see https://www.palgrave.com/de/book/9783319703732.

Pound, no major modernist of the period wrote original, non-essayistic work for the medium. The first of his so-called 'radio operas', The Testament of François Villon, was aired by the National Programme on 26 October 1931, but the second, Cavalcanti, remained unfinished (see Fisher 2002). Eliot, by contrast, agreed to a radio adaptation of The Waste Land in 1937, but would 'refuse BBC Producer Archie Harding's invitations to employ radio as a medium for serious writing' (Avery 2006: 116). As such, modernists perceived broadcasting first and foremost as an additional outlet for their poetry, prose, and criticism, not as a form of creative expression in its own right.

This is not to say, however, that radio had no creative potential for the modernists, for it did significantly impact on their work in the more traditional and established genres. In Woolf's mock-biographical novel Orlando (1928), radio instils the androgynous protagonist with a renewed sense of 'magic' when she reflects on the 'fabric of life now', especially its wireless nature: 'In the eighteenth century, we knew how everything was done; but here I rise through the air; I listen to voices in America; I see men flying - but how it's done, I can't even begin to wonder. So my belief in magic returns' (2008: 174). This notion of the 'voice' and its prominence in modernist literature, especially the polyphony of different voices and their fragmentation, is often connected to broadcasting. Katherine Mullin, for example, describes Eliot's The Waste Land (1922) as 'a noisy poem, packed with colliding sounds' in which many '[v]oices compete, displacing one another, as if the listener is tuning an analogue radio' and switching 'between stations' (2016). An even more radical example is James Joyce, as Jane Lewty explains. The 'principal motif' in book two, chapter three of Finnegans Wake (1939) is radio, 'whose continual presence ensures that all dialogue is loud, rapid and fragmented' (2007). The chapter opens with 'tolvtubular high fidelity dialdialler' (Joyce 2000c: 309), so that the turning of a radio dial sets off a cacophony of voices and distorted sounds, which becomes the stylistic principle of the chapter. Lewty already detects an influence of broadcasting on the stream of consciousness technique as it is used in Ulysses (1922), suggesting that 'Joyce's incessant, restless switching [...] invites the comparison between a mind in transit and a radio being manually operated' (2005). Woolf, too, links broadcasting to the mind in her essay 'Three Guineas' (1938), urging her reader to 'turn on the wireless' and 'consult the findings of the public psychometer for yourself' (1996: 179). This remark makes it all the more surprising that the author who urged modern fiction to 'look within' did not see or recognize the potential that radio had to offer in this direction, 
This is the author's version of a chapter published by Palgrave Macmillan in Beckett and Modernism, ed. Olga Beloborodova, Dirk Van Hulle and Pim Verhulst (New York, 2018),

239-258. Please refer to the published version for correct citation and content. For more information, see https://www.palgrave.com/de/book/9783319703732.

especially since various later critics, like John Drakakis, agree that 'what the medium could do best was to represent the psychological processes of the human mind' (1981: 24).

Even if canonical modernists like Woolf, Eliot and Joyce did not write fiction for the medium directly, 'the relationship between modernism and the radio was a symbiotic one', Angela Frattarola argues:

the technology of the radio presented a model for modernist writers, showing them how noises, voices, and music could be juxtaposed in new ways and exposing them to new forms, while modernist writers influenced how radio programs were shaped and what aesthetic possibilities were available to the writer of radio drama. (2009: 465)

Frattarola goes on to show that during the late 1920s and 1930s, modernist poetry and prose were instrumental in helping early radio drama break free from the conventions of the theatre - which in that period was regarded as 'antimodernist' (Innes 2011: 128) - by encouraging radio dramatists to experiment with new techniques like fragmentation, multiperspectivism, mythic paradigms and stream of consciousness. This led to a particular strand of 'microphone play' that was 'from the start, predisposed to modernist aesthetics' (2009: 450) because, like modernist literature, the 'undistracted listening' it demanded, 'involved a level of difficulty that required a more attentive ear and focused concentration' (452). While some authors truly warrant this comparison in the way they apply the monologue interieur, for example Tyrone Guthrie in his radio plays The Flowers Are Not for You to Pick (1929) and Matrimonial News (1931), others, such as Val Gielgud, Lawrence Du Garde Peach and D. G. Bridson, remain 'conventional in form', even if they 'tend to align themselves with modernist sensibilities' in their content (461).

That radio drama did not become a breakthrough genre for modernism during this period in Britain, is mostly due to the prewar institutional context of broadcasting. There was only one network, which had to cater to the entire country, and the BBC followed a strong unifying 'one nation, one network' policy under its conservative General Director John Reith (see Whitehead 1989), especially during the war (see Dinsman 2015). This situation changed notably after the Second World War, when a three-network structure was created. In this constellation, the Home and Light services attended to the general public, while the Third Programme was reserved for the arts. Although listening figures for the Third were quite low, 
This is the author's version of a chapter published by Palgrave Macmillan in Beckett and Modernism, ed. Olga Beloborodova, Dirk Van Hulle and Pim Verhulst (New York, 2018),

239-258. Please refer to the published version for correct citation and content. For more information, see https://www.palgrave.com/de/book/9783319703732.

comparatively, the network generated much esteem and influence among its, mostly but not exclusively, (upper-)middle-class and educated audience. It would certainly be wrong to say that the network was staunchly avant-garde in all its aspects, but for the first time in Britain a radio platform was created that strove to offer its audience the best selection of culture and actively encouraged experiment (see Carpenter 1997: 239-40).

In this context, on 25 January 1954, the first modernist masterpiece for radio, Under Milk Wood by Dylan Thomas, was broadcast, in Douglas Cleverdon's lauded production. As the narrating voice hovers over the fictional Welsh seaside town of Llareggub - palindrome of 'Buggerall' - it variously dips 'behind the eyes of the sleepers' to register 'the movements and countries and mazes and colours and dismays and rainbows and tunes and wishes and flight and fall and despairs and big seas of their dreams' (Thomas 2014: 4). In addition to moving in and out of the characters' minds at night, to eavesdrop on their innermost desires and fears, the narrator goes on during the day, juxtaposing scraps of dialogue, thoughts and asides. The resulting fragmentary multitude of impressions again resembles a radio receiver jumping erratically from station to station, with the narrator announcing the programmes and setting the scene. In this combination of omniscient narrator with stream of consciousness technique, and the use of sonority with free association unhindered by rigid plot, Barbara Hardy recognizes a 'debt to Joyce - not only to Ulysses but also to the great and poetic novel of the night, Finnegans Wake' (2000: 57). By referring to Under Milk Wood as 'Thomas's Ulysses' (65), Hardy puts his significance for radio on a par with that of Joyce for prose and, by extension, that of Eliot, with the help of Pound, for poetry. If we agree that this moment marks the belated arrival - or rather the crowning achievement - of 'high' modernism for the medium, lagging 32 years behind the rest, then the addition of radio drama as a form of literary expression significantly broadens the canonical timeframe. It also begs the question how authors following Dylan Thomas dealt not only with the legacy of Under Milk Wood in particular, but with that of high modernism in general.

Beckett had no small shoes to fill when in June 1956 the BBC asked him to write a radio play for them. Unanimously praised as one of broadcasting's greatest achievements, it is likely that Under Milk Wood came up during one of Beckett's meetings with BBC staff to discuss his script, as an example of what they were looking for, and when All That Fall was aired, on 13 January 1957, the two radio plays were often compared in press reviews and internal BBC staff memos. Beckett appears to have been familiar with the text, because when 
This is the author's version of a chapter published by Palgrave Macmillan in Beckett and Modernism, ed. Olga Beloborodova, Dirk Van Hulle and Pim Verhulst (New York, 2018),

239-258. Please refer to the published version for correct citation and content. For more information, see https://www.palgrave.com/de/book/9783319703732.

Alan Simpson, the director of the Dublin Pike Theatre, revealed his plans for an adaptation of All That Fall similar to the production of Under Milk Wood in the West End, Beckett refused claiming that the stage presentation of Thomas's radio play was regrettable. ${ }^{3}$ While this is as far as his critical assessment goes, Beckett is known to have disliked Thomas's 'fat poems', as well as the 'pulpit voice', 'hyperarticulation and sibilation' with which he read them on the air (LSB III 184). In light of this scathing verdict, Beckett will not have appreciated the poetic style of the radio play. And, having already dismissed Joyce' Ulysses in 1937 because it "falsifies the unconscious, or the "monologue intérieur," in so far as it is obliged to express it as a teleology' (qtd. in Nixon 2011: 167), he no longer seemed to consider the stream of consciousness technique a viable method either. However, even if he believed that some of the stylistic devices typifying modernism were well-worn by the mid-1950s, he did continue to share its interest in the mind and the way it is embedded in the world. A crucial difference in this respect is that Beckett shifted the attention away from the representation of characters' thoughts to the workings of the mind and cognition itself, in turn obfuscating the boundary between inside and outside that is still maintained in most modernist fiction.

The mind/world relationship was high on the agenda not only in literary modernism. Other contemporary disciplines, such as philosophy, psychology, and science, also displayed a renewed interest in the subject, planting the seeds of what would later become known as cognitive science and would eventually lead to revolutionary insights in the present-day philosophical and scientific debate on the nature of human cognition.

\section{The rise of (post)cognitivism}

The idea of a close interaction between the human brain and the environment it operates in goes back a long way but rose to unprecedented prominence during the early modernist period. Consider, for example, William James' treatment of consciousness as a relation rather than content, ${ }^{4}$ or phenomenology's emphasis on the experiencing subject. However, the $20^{\text {th }}$ century also witnessed a paradigm shift away from the notion of experience, partially as an attempt to move away from psychologism on the one hand and behaviourism on the other. The birth of analytic philosophy at the turn of the century and its later transformation into cognitive science in the 1950 s, with rudimentary yet rapidly developing computers, has lead to a fixation on the representational and computational models for the human brain. Such models imply that human cognition turns on two essential ingredients: (1) mental 
This is the author's version of a chapter published by Palgrave Macmillan in Beckett and Modernism, ed. Olga Beloborodova, Dirk Van Hulle and Pim Verhulst (New York, 2018),

239-258. Please refer to the published version for correct citation and content. For more information, see https://www.palgrave.com/de/book/9783319703732.

representations of the world that are formed on the basis of perceptual information, and (2) a set of rules that manipulate these representations, whereby - crucially - 'both the representations and the operations by which they are transformed are internal to the brain' (Rowlands 2010: 30). They assume that sensorimotor and environmental factors merely cause cognitive processes to occur inside the brain; in no way do they participate in cognition properly so-called. Artificial Intelligence - the most celebrated result of the mind-machine principle - became the new darling of the science world, and both experience and materiality further faded into the background. Fortunately, in the past few decades it has become clear that the clinical abstraction that underlies AI does not bring us much closer to solving the mystery of the human mind. As a result, an alternative, postcognitivist paradigm has been emerging both in philosophy and cognitive science - one that brings the environment and material objects back into the spotlight of scientific scrutiny.

Extended cognition - an umbrella term for postcognitivist models used interchangeably with active externalism and distributed cognition - insists on a dynamic and constitutive interaction between the biological brain, the rest of the body, and the environment. Departing from a simple question - 'Where does the mind stop and the world begin?' (Clark and Chalmers 2010: 27) - the proponents of extended cognition attempt to deal a significant (if not fatal) blow to the hegemony of the Cartesian mind that has reigned supreme for centuries in the western world, and thus dispense with the ubiquitous principle of $\mathrm{mind} /$ world dualism it entails.

For the present chapter, two theories of extended cognition will be discussed in connection with Beckett's radio plays, one more radically anti-Cartesian than the other. The less radical one is the extended mind thesis: according to its founding fathers, Andy Clark and David Chalmers, the extended mind thesis straddles the internal human brain and external objects (both material and immaterial) in a so-called hybrid or extended cognitive system. The idea is that both elements - neural and extracranial - are equally important for extended cognition to take place. As Richard Menary said, in extended cognition 'the human organism is linked with an external entity in a two-way interaction, creating a coupled system that can be seen as a cognitive system in its own right. [...] If we remove the external component the system's behavioural competence will drop, just as it would if we removed part of its brain' (2010: 29). The extended mind thesis underwrites the traditional assumption that cognition is essentially information processing, and the only way to process information 
This is the author's version of a chapter published by Palgrave Macmillan in Beckett and Modernism, ed. Olga Beloborodova, Dirk Van Hulle and Pim Verhulst (New York, 2018),

239-258. Please refer to the published version for correct citation and content. For more information, see https://www.palgrave.com/de/book/9783319703732.

is to turn it into some form of representation. What it disputes, however, is the necessarily intracranial location of representations, claiming that they can also be external and functionally similar to their internal counterparts.

Unlike the extended mind thesis, enactivism, the more radical member of the postcognitivist family, categorically rejects the representational account of cognition and states that cognitive processes take place during the intelligent agent's unmediated interaction with their surroundings. In their programmatic text The Embodied Mind: Cognitive Science and Human Experience (1991), Varela, Thompson and Rosch turn to another modernist, the French phenomenologist Maurice Merleau-Ponty, who emphasized the importance of the body for human cognition and saw 'our bodies both as physical structures and as lived, experiential structures' (xv). They endorse Merleau-Ponty's view that 'embodiment has a double sense: it encompasses both the body as a lived, experiential structure and the body as the context or milieu of cognitive mechanisms', noting that 'embodiment in this double sense has been virtually absent from cognitive science' (xvi). This is how Varela et al. formulate the challenge of their enactivist theory:

In the enactive program, we explicitly call into question the assumption - prevalent throughout cognitive science - that cognition consists of the representation of a world that is independent of our cognitive and perceptual capacities by a cognitive system that exists independent of the world. (xx)

More recently, Di Paolo, Rohde and De Jaegher (2010) have developed a set of five elements that constitute an enactive cognitive system, namely 1) autonomy or self-generation, 2) sense-making, 3) emergence, 4) embodiment, and 5) experience. Particularly interesting for our purpose is the focus of the enactive mind on sense-making activity, as all Beckett's radio plays thematize this issue, especially the later ones.

Even this brief description of the two major postcognitivist strands reveals important differences in the way they situate the cognizing agent within its environment. Here, too, a continuum of sorts can be distinguished: while the extended mind thesis, with its foregrounding of external objects as parts of a hybrid cognitive system, still implicitly acknowledges the existence of the internal/external divide, enactivism abandons this - in their eyes still Cartesian - premise and reconceptualizes cognition as a perpetual feedback 
This is the author's version of a chapter published by Palgrave Macmillan in Beckett and Modernism, ed. Olga Beloborodova, Dirk Van Hulle and Pim Verhulst (New York, 2018),

239-258. Please refer to the published version for correct citation and content. For more information, see https://www.palgrave.com/de/book/9783319703732.

loop with no pre-given representational structures stored in the neural brain. In this connection, the nature of the radio medium is particularly interesting, because radio is often intuitively perceived as something ephemeral, lacking the physical characteristics of a proper object anchored in space and therefore clearly external to the cognizing agent. Beckett's radio plays show a development from one end of the spectrum to the other, with Rough for Radio II signifying something of a watershed.

\section{Beckett's radio plays: a postcognitivist continuum}

As many commentators have noted, there is a clear evolution in Beckett's radio drama, both in terms of setting and characters. Germaine Baril (1987), for example, noted a shift from 'characters' or 'dramatis personae' to 'events'. Examined from a postcognitivist perspective, the radio plays also show a transition from a more traditional representational model of the Cartesian mind towards evocations of cognitive processes themselves, in an environment increasingly stripped of any distinctive features. However, this shift does not necessarily signify a form of inward turn - instead, the ubiquitous dualist divide dissipates, and environmental elements are still present and sometimes even dominant, albeit in a different, perhaps less material form. We should also bear in mind that the postcognitivist mind models that can be discerned in the radio plays - either extended or enactive - do not lead to an improved cognitive performance or help the mind attain any particular goal, as they are expected to by their proponents. At the same time, a system does not have to be successful in order to assert its existence, and this holds particularly true for Beckett's poetics of failure: whether Cartesian, extended or enactive, the Beckettian mind remains bewildered, exasperated, 'in dimmost dim' (CIWS 103).

In the postcognitivist continuum the radio plays represent, we distinguish the following scale: All That Fall is the most 'Cartesian' piece, with a seemingly clear demarcation between Maddy's inner mental state and the intrusive, noisy, and overbearing storyworld she navigates. All the same, she constantly interacts with that world, sometimes in an extended way, an example of which will be discussed below. The next piece - Embers - is perhaps the most challenging one for an extended cognitive analysis, because of the ambiguous status of the storyworld. From Rough for Radio II onwards, ${ }^{5}$ the mind's representation model - extended or not - no longer applies, and we are moving into the enactivist realm, toward a seamless amalgamation of internal and external components in 
This is the author's version of a chapter published by Palgrave Macmillan in Beckett and Modernism, ed. Olga Beloborodova, Dirk Van Hulle and Pim Verhulst (New York, 2018),

239-258. Please refer to the published version for correct citation and content. For more information, see https://www.palgrave.com/de/book/9783319703732.

which the distinction loses relevance. However, we shall discover that the enactivist model, with its emphasis on the active role for the cognizing agent, will also show signs of abatement, as the cognizing agent will increasingly lose control of its environment and will be reduced in the end from 'Animator' to a mere 'Opener', not unlike someone turning on the radio and surrendering oneself to whatever sounds - be it words or music - emerge from it.

\section{All That Fall}

In his analysis of the radio play, Everett Frost suggests that 'it takes place entirely inside the mind of Maddy Rooney' (2014: 255), but it would perhaps be more correct to say that she is the focalizer of the events through which all perceptions are mediated for the audience. As she rather self-consciously states, 'I see it all', referring to her surroundings, which include the train station, the racecourse, the hills and her bystanders (ATF 17). While BBC producer Donald McWhinnie deliberately altered many of the sound effects, to mark them as filtered through Maddy's distorted - perhaps even deranged - perception, there is still clearly a material world that exists outside and independently of her. ${ }^{6}$ Although using the protagonist (rather than the narrator) as focalizer does invoke a sense of greater interiority, the environment is never far off, as Maddy is deeply embedded in her storyworld, and instances of extended cognition can be found with relative ease. The first one occurs straight away at the opening scene, when Maddy overhears the music emanating from a house she is passing:

Rural sounds. Sheep, bird, cow, cock, severally, then together. Silence. MRS ROONEY advances along country road towards railway station. Sound of her dragging feet.

Music faint from house by way. 'Death and the Maiden'. The steps slow down, stop.

MRS ROONEY: Poor woman. All alone in that ruinous old house. [Music louder. Silence but for music playing. The steps resume. Music dies. MRS ROONEY murmurs, melody. Her murmur dies. (3)

Towards the end of the play, the music returns in a similar way: 
This is the author's version of a chapter published by Palgrave Macmillan in Beckett and Modernism, ed. Olga Beloborodova, Dirk Van Hulle and Pim Verhulst (New York, 2018),

239-258. Please refer to the published version for correct citation and content. For more information, see https://www.palgrave.com/de/book/9783319703732.

[They move on. Wind and rain. Dragging feet, etc. faintly same music as before. They halt. Music clearer. Silence but for music playing. Music dies.] [MRS ROONEY:] All day the same old record. All alone in that great empty house. She must be a very old woman now. (30)

The moment it perceives Schubert's music, Maddy's brain forms a hybrid cognitive system with that music. Although such a system normally implies the manipulation by the cognizing agent of some tangible object (such as the writer using pen and paper to compose text), the principle can be extrapolated to immaterial entities (as mentioned before, immateriality and interiority are not synonymous notions). What is important is that the external element is 'active, playing a crucial role in the here-and-now', and therefore ' $\mathrm{ha}[\mathrm{s}]$ a direct impact on the organism and on its behavior' (Clark and Chalmers 2010: 29). The result of the extended cognitive activity is an image of some 'poor woman' who is apparently 'all alone in that ruinous old house'. In general, the play is grounded in Maddy's continuous interaction with her environment: throughout her laborious trip to the station, she constantly comments on what she sees and engages in conversation - often against her will - with passers-by, which in turn, triggers a number of short interior monologues. Besides, Maddy's mind is also anchored in Maddy's sprawling body and is directly affected by her sensorimotor experience.

\section{Embers}

Quite different is Beckett's second radio play, Embers, which consistently maintains ambiguity over the ontological status of the play's storyworld. The most obvious example here is the presence of Henry's wife Ada: shortly after her appearance in the text she places her shawl under Henry, which seems to confirm her corporeal presence at the scene, yet the stage directions specifically mention '[No sound as she sits.]' (ATF 39), suggesting exactly the opposite. As Clas Zilliacus (1976: 83) and Rosemary Pountney (1988: 107-9) have shown in their genetic studies of the radio play, the passages that complicate Ada's physical presence were heavily revised, showing Beckett's hesitation as to how far he could push the technique in the sightless medium of radio. To Roger Blin, he even explained why Embers should not be staged: 'when you listen, you don't know if Ada exists or not, whether she only exists in the imagination of the character Henry' (Blin 1994: 310). Even though the boundary between the inside and the outside of Henry's skull is obscured as a result, the distinction 
This is the author's version of a chapter published by Palgrave Macmillan in Beckett and Modernism, ed. Olga Beloborodova, Dirk Van Hulle and Pim Verhulst (New York, 2018),

239-258. Please refer to the published version for correct citation and content. For more information, see https://www.palgrave.com/de/book/9783319703732.

obviously still matters, since it is the foundation on which the entire listening experience is built.

Similarly, the presence of the sea is constantly underscored and questioned at the same time: the play opens with the sound of the sea and Henry's boots on the shingle (ATF 35), placing the protagonist ostensibly on the sea shore. However, in his opening speech (while talking to the apparition of his dead father), Henry says the following:

That sound you hear is the sea. [Pause. Louder.] I say that sound you hear is the sea, we are sitting on the strand. [Pause.] I mention it because the sound is so strange, so unlike the sound of the sea, that if you didn't see what it was you wouldn't know what it was. (35)

At this point it matters little whether Henry is addressing his father or the audience, since both are equally blind and can only rely on their hearing for guidance. We can assume the sea is actually there, and that Henry is actually on the shore, because unlike some other sounds (such as the hooves or the drip), the sound of the sea is never prompted by Henry himself, and we also hear him walk on shingle, which adds to the illusion of his 'being there'. However, this is again ambiguated by the fact that Beckett wanted the sea to be unrealistic and stylized in his production notes for Donald McWhinnie, which is also how it is conveyed in the $\mathrm{BBC}$ version of the radio play. ${ }^{7}$ As with Maddy, this would suggest that the sound is filtered by his perception, but the result is more radical and disorienting. The mixed feelings the sea invokes in Henry's mind - he loathes it but cannot seem to stay away from it at the same time - underscore its importance for Henry's life, as he seems to be engaged in constant dialogue with it. Henry's interaction with the sea as part of his storyworld can be seen as a good example of how modernist fictional minds 'at once shape and are shaped by larger experiential environments' (Herman 2011: 249-50). The closing words of the play - the opposition of Henry's 'Not a sound' (ATF 47) and the sound of the sea indicated in the stage directions - further capture the ambiguity as to the ontological status of the storyworld. By obstructing the ostensibly clear internal/external dichotomy, this ambiguity - enhanced by the 'blind' radio medium - further effaces the Cartesian dualist mind/world boundary. In the plays that follow, this boundary will disappear almost entirely, thus creating the optimal conditions to approach them from an enactivist perspective. 
This is the author's version of a chapter published by Palgrave Macmillan in Beckett and Modernism, ed. Olga Beloborodova, Dirk Van Hulle and Pim Verhulst (New York, 2018),

239-258. Please refer to the published version for correct citation and content. For more information, see https://www.palgrave.com/de/book/9783319703732.

\section{Rough for Radio II}

Rough for Radio II has been discussed by several commentators as a representation or evocation of cognitive activity, mostly related to the process of artistic creation. ${ }^{8}$ The idea was launched by Martin Esslin, when he summarized the play in the following terms:

If we see Rough for Radio as a monodrama about the artistic process in which each of the characters represents one aspect of the artist's mind, we must regard the Animator as the Critical faculty trying to shape the utterances of the voice that emerges from the subconscious, while the stenographer is the recording faculty and, also, in her distress about the spurious sentence the Animator inserts in the text, the artist's conscience; Dick, the torturer, is the artist's determination to stimulate his subconscious by suffering; the stenographer's disrobing and kissing of Fox represents analogous attempts to stimulate the subconscious by erotic fantasies. (1977: 101-2)

What we propose here is another cognitive reading of the play, but the cognitive system sketched here will be an enactive one, in which the characters not just represent aspects of the mind (to borrow Esslin's terminology), but together evoke an enactive cognitive system a system that can be described using the five properties of an enactive mind devised by Di Paolo et al. (2010) and mentioned earlier in this chapter: autonomy, sense-making, emergence, embodiment, and experience.

To begin with, the constellation that the four characters invoke can be considered autonomous, whereby autonomy by no means denotes isolation from outside influences: 'Living organisms are autonomous [because] they follow laws set up by their own activity. Fundamentally, they can be autonomous only by virtue of their self-generated identity as distinct entities' (Di Paolo et al. 2010: 37). The emphasis here lies firmly on autopoiesis - a process by which a self-sustaining system can maintain itself in a dynamic way, using neural and environmental resources and constraints available. Similarly, the interaction between Animator, Stenographer, Fox and Dick follows a well-defined set of rules, assigning to each a particular role in the process. The system is self-contained, since no one joins in or drops out in the course of the radio play, and the participants depend on each other for the system to continue functioning (something known as 'operational closure' (38)). Moreover, its cyclical 
This is the author's version of a chapter published by Palgrave Macmillan in Beckett and Modernism, ed. Olga Beloborodova, Dirk Van Hulle and Pim Verhulst (New York, 2018),

239-258. Please refer to the published version for correct citation and content. For more information, see https://www.palgrave.com/de/book/9783319703732.

structure - the idea that this quest has been going on for a long time and will continue for at least some time in the future - is another sign of the self-generative nature of the system. Furthermore, the characters are collectively engaged in a process of sense-making, or generating meaning through their encounters with the environment. Within that system, it is Fox (cf. Latin vox) who can be seen as the external element, because he is supposed to harbour some form of meaning that the system is trying to extract. Crucially, this process of sense-making is

an inherently active idea. Organisms do not passively receive information from their environments, which they then translate into internal representations. [...] They participate in the generation of meaning through their bodies and action often engaging in transformational and not merely informational interactions; they enact a world. (39)

Indeed, the very term 'Animator' - the character who stands for the 'intellect', according to Pountney's description (1988: 114) - suggests a highly active role for the cognizing agent, and he lives up to his name by constantly adjusting his interrogation techniques, based on his experience with Fox during previous sessions. As the potential source of the redeeming 'sign or set of words' (ATF 66), Fox's speeches seem to make little sense, and meaning has to be assigned to them by the system, rather than by himself: in enactivist terms, '[m] eaning is not to be found in elements belonging to the environment or in the internal dynamics of the agent, but belongs to the relational domain between the two' (Di Paolo et al. 2010: 40). Fox also has to wear a gag in between the sessions, in order to avoid 'the least word let fall in solitude and thereby in danger [...] of being no longer needed' (ATF 60), so that meaning can be generated outside the framework of the system.

Despite his dominant presence, the control Animator seems to exert over Fox and his own subordinates is little more than an illusion - a far cry from the powerful Cartesian mind reigning supreme over its body and the world at large. Animator is just another part of the system, almost no different in significance from Stenographer, who brings in the mnemonic function, or Dick, whose role is almost exclusively physical. Staying with the physical, the issue of embodiment - so paramount in enactivism - is surprisingly pertinent in the play, especially considering Beckett's own characterization of radio as intended for 'voices' and 
This is the author's version of a chapter published by Palgrave Macmillan in Beckett and Modernism, ed. Olga Beloborodova, Dirk Van Hulle and Pim Verhulst (New York, 2018),

239-258. Please refer to the published version for correct citation and content. For more information, see https://www.palgrave.com/de/book/9783319703732.

stage plays as intended for 'bodies', as he told Barney Rosset in his letter of 27 August 1957 (LSB III 63). There are a number of sexual innuendos, and corporal punishment administered by a bull's pizzle - is being used to instigate the meaning-making activity. Finally, the emergent nature of the system is illustrated by the speeches produced by Fox, each failing to meet the team's expectations and thus precipitating another round of interrogation. What thus emerges from this particular enactive cognitive system is nonmeaning rather than meaning: in other words, the system fails time and again.

Compared to its earlier counterparts, Rough for Radio II clearly demonstrates a shift in Beckett's approach to radio drama. Here, the Beckettian mind is not represented anymore - it is enacted as a living, dynamic, self-generating cognitive system that operates by trial and error, fumbling and stumbling in the dark, and failing to succeed in its sense-making activity. The ubiquitous dualist boundary, clearly present in All That Fall and still palpable in Embers, gives way to an enactive amalgamation of inside and outside, thus becoming a non-issue. The Cartesian subject, the ostensibly almighty cogito wielding control over its environment, has received a near-fatal blow and will not regain its former strength, as the three subsequent radio plays so poignantly illustrate.

\section{Words and Music, Rough for Radio I, Cascando}

Also known as 'text-music tandems' (Beckett qtd. in Zilliacus 1976: 99), these three later radio plays continue the deterioration of the cognizing agent by increasingly passivizing its role within an enactive cognitive system. In Words and Music, non-human characters first enter the stage (or, more appropriately, the ether). The figure of Croak, despite the club that he wields, does not emanate the same degree of authority as the Animator, and he ultimately fails to exert any form of control over the environmental inputs of Words and Music, leaving him no choice but to leave with 'shuffling carpet slippers' (ATF 73). Similarly, in Rough for Radio I, it gradually becomes obvious just how dependent Macgillycuddy is on the very things he is supposed to control, as his 'need' is poignantly illustrated by the panic he experiences during the phone call to the doctor: '[Music and voice silent. Very agitated.] Yes...yes...no matter... what the trouble is?...they're ending...ENDING...this morning...what?...no!...no question!...ENDING I tell you... [...] I tell you they're ending...ENDING...I can't stay like this after...' (55). Macgillycuddy's exasperation offsets his capacity to wield the knobs and thus control environmental elements, as he makes clear 
This is the author's version of a chapter published by Palgrave Macmillan in Beckett and Modernism, ed. Olga Beloborodova, Dirk Van Hulle and Pim Verhulst (New York, 2018),

239-258. Please refer to the published version for correct citation and content. For more information, see https://www.palgrave.com/de/book/9783319703732.

that without those elements he, too, will cease to exist. Rough for Radio I unexpectedly reintroduces material elements such as the curtain (a possible mind-world separator) and the knobs to manipulate the sounds, but we must keep in mind that the text remained unfinished, lacking the role of Voice, and that it was not published until the early 1970s. In fact, Beckett abandoned it to start drafting Cascando the very next day, undoing these material elements in the process.

Beckett's last radio play represents the crystallization of his approach to radio. Clas Zilliacus reads Cascando 'as a sequel to Esquisse [radiophonique] in the sense that it cuts all ties with the external world', a text that conveys 'pure, mental matter without spatial dimensions and associations' (122). This interpretation of Cascando is affected by the removal of spatial and external elements that were present in Rough for Radio I, which Zilliacus is right to consider 'a kind of proto-Cascando' (119). However, as we mentioned above, immateriality does not necessarily equal interiority, as the act of opening and closing in Cascando testifies:

OPENER: [...] What do I open?

They say, He opens nothing, he has nothing to open, it's in his head.

They don't see me, they don't see what I do, They don't see what I have, and they say, He opens nothing, he has nothing to open, it's in his head.

I don't protest any more, I don't say any more,

There's nothing in my head.

I don't answer any more.

I open and close. (ATF 88)

Although the opening and closing produces a vivid image of a clear boundary (probably the head), the fragment seems to suggest that the container itself is empty and opens every now and then to absorb environmental elements (be it voice or music). The return of the dualist 'Cartesian' terminology may be a little surprising at this stage, especially because the play clearly lacks the material objects that its predecessors still had. Besides, Opener's assertion should perhaps not be taken at face value: it is not impossible to imagine that voice and music do in fact come from 'within' rather than 'without', but the main difference with Words and 
This is the author's version of a chapter published by Palgrave Macmillan in Beckett and Modernism, ed. Olga Beloborodova, Dirk Van Hulle and Pim Verhulst (New York, 2018),

239-258. Please refer to the published version for correct citation and content. For more information, see https://www.palgrave.com/de/book/9783319703732.

Music and Rough for Radio I is that Cascando again introduces an additional layer of confusion and complexity. Compared to the situation in All That Fall, where the music was unequivocally identified as coming from a house Maddy was passing by, the music's origin in Cascando is much more ambiguous, precisely because the storyworld in the more traditional sense of the word is absent in the play.

Considered from an enactivist angle, a different picture emerges: the enactive cognitive system, with the cognizing agent reduced to a mere Opener, has to rely on an impoverished environment (Voice and Music) in order to self-generate and continue its sense-making activity. The environmental elements fill the Opener's head, which is otherwise vacant (or so it is suggested by the Opener himself) - an image that could serve as an illustration to the most radical variety of enactivism, known as the extensive mind thesis (developed by Daniel Hutto and Erik Myin in 2013). Hutto and Myin argue that the basic human mind is entirely content-free (or vacant) and draws all the information it needs from its immediate environment. For more sophisticated kinds of cognitive activity, the basic mind relies entirely on external scaffolding, such as linguistic, social, and cultural practices (1512). This radical enactive reading of the Opener's extensive or content-free mind is by no means the only possible interpretation of Cascando's enigmatic message, but it does offer a plausible alternative to the play's alleged inward focus.

\section{Beckett's postcognitivist modernism}

The aim of the postcognitivist continuum sketched here for Beckett's radio plays was to demonstrate his move from a more traditional representational account of the mind to an attempt at showing that cognition emerges in a continuous interaction between the cognizing agent and the environment, even if the latter consists merely of sound (music and spoken words). This conclusion can be extrapolated to Beckett's oeuvre in general, be it prose, in which L'Innommable could be considered the turning point, or drama, where the radio plays had a decisive part to play in the process. The Beckettian subject - hardly a celebration of the Cartesian cogito from the very start - becomes more and more vulnerable and dependent on extracranial elements, failing to exert control over them and assuming an increasingly passive role. Moreover, none of the cognitive systems evoked in Beckett's works - whether extended or enactive - ever come to fruition and produce a successful result, despite the 'thoughtenhancing' properties those theories claim to harbour. However, there is something resilient 
This is the author's version of a chapter published by Palgrave Macmillan in Beckett and Modernism, ed. Olga Beloborodova, Dirk Van Hulle and Pim Verhulst (New York, 2018),

239-258. Please refer to the published version for correct citation and content. For more information, see https://www.palgrave.com/de/book/9783319703732.

in Beckett's poetics of failure, and his work, propelled by the ever-present 'on', emanates continuous creative energy - something H. Porter Abbott labels 'the anxiety of modernism' (1996: 27-32). In other words, despite its diminishing role, the Beckettian mind refuses to retreat into the shell of Cartesian representationalism. Rather than taking an inward turn, Beckett's postcognitivist modernism demonstrates that however mutable, minimal and immaterial, the environment is inseparable from the struggling yet enduring enactive mind, trapped in a self-generating, emergent cognitive system and, despite being 'doomed to fail', trying against all odds to make sense of the world.

\section{Notes}

The research leading to these results has also received funding from the European Research Council under the European Union's Seventh Framework Programme (FP7/2007-2013) / ERC grant agreement n $\mathrm{n}^{\mathrm{O}} 313609$.

1. Die Verinnerung des Erzählens, first published in German in 1957 and 1959, and in English in 1973.

2. In an attempt to move away from Cartesian dichotomies, Herman devises his own continuum, one 'between, at one pole, a tight coupling between an intelligent agent and that agent's surrounding environment, and, at the other pole, a looser coupling between agent and environment' (249).

3. See letter from Samuel Beckett to Alan Simpson, dated 15 January 1958 (TCD 10731-56).

4. Cf. James' famous essay, 'Does “Consciousness” Exist?' (1904).

5. Although Pochade radiophonique (Rough for Radio II) is often situated in the early 1960 s, a late 1950s origin seems more likely. For more information about this alternative dating, see Verhulst 2015 and 2017.

6. See McWhinnie 1959: 133-51.

7. These production notes were made on a typescript now held at the University of Reading (UoR MS 1396-4-6), but they have never been incorporated in any printed edition of the text. Recordings of Beckett's radio plays are available on CD from the $\mathrm{BBC}$ and the British Library. 
This is the author's version of a chapter published by Palgrave Macmillan in Beckett and Modernism, ed. Olga Beloborodova, Dirk Van Hulle and Pim Verhulst (New York, 2018),

239-258. Please refer to the published version for correct citation and content. For more information, see https://www.palgrave.com/de/book/9783319703732.

8. Apart from Esslin, Rosemary Pountney (1988: 114) also noted the radio play's connection to the problem of authorship. Dirk Van Hulle (2011: 222-3 and 2015b: 231-2) offers a more detailed cognitive reading: he sees the four characters in Rough for Radio II as evocations of four cognitive functions in the process of creation but uses them in a slightly different context, namely to elucidate how the process of composition (or genesis) can be thematized in a narrative. 